\title{
基于创新型化学专业学生培养的有机化学教学改革与实践
}

\author{
惠新平 ${ }^{*}$, 武全香 \\ 兰州大学化学化工学院, 兰州 730000
}

摘要: 基于创新型化学专业学生培养, 兰州大学有机化学课程持续进行教学改革与实践, 本文从有机化学课程目标、 改革举措、创新特色、教学评价及改革成效等方面进行了总结, 以进一步提高课程教学质量。

关键词: 有机化学; 教学改革; 人才培养

中图分类号: G64; O6

\section{Teaching Reform and Practice of Organic Chemistry Course Based on Innovative Chemistry-Majored Students Cultivation}

Xinping Hui ${ }^{*}$, Quanxiang Wu

College of Chemistry and Chemical Engineering, Lanzhou University, Lanzhou 730000, P. R. China.

\begin{abstract}
Based on the cultivation of innovative chemistry-majored students, the teaching reform and practice of organic chemistry course in Lanzhou University have been carried out continuously. This paper summarizes the teaching reform and practice from course goals, reform methods, innovational features, teaching evaluation and reform effect in order to further improve the teaching quality.
\end{abstract}

Key Words: Organic chemistry; Teaching reform; Talents cultivation

\section{1 引言}

随着建设创新型国家和实施人才强国战略, 国家对化学拔尖创新人才培养提出了更高要求。围 绕化学拔尖创新人才培养, 国内许多高校进行了积极的探索和实践 ${ }^{[1]}$ 。进行拔尖创新人才培养, 需 要不断进行教学改革, 创新教学方法和培养模式。兰州大学化学化工学院在国家理科基础科学研究 与教学人才培养基地建设和化学拔尖学生培养试验计划的实践中, 持续进行课程体系 ${ }^{[2]}$ 和专业课程 教学改革。

有机化学一直是发现、创造新物质的重要科学前沿, 有机化学课程主要讲授有机化合物的结构、 性质及其变化规律和与此相关的基本理论, 是一门理论与实践结合紧密的课程。有机化学课程是本 院化学、应用化学、化学工程与工艺、功能材料和能源化学工程专业的专业基础课, 108 学时, 每年 选课人数约 280 人。课程紧密依托兰州大学功能有机分子化学国家重点实验室和有机化学国家重点 学科, 是 “国家理科基地名牌课程” 和 “甘肃省精品课程”, 课程教学团队入选甘肃省教学团队, 是 “基础理论与实验能力双高型化学专业课程” 国家级教学团队的骨干力量。作为化学专业学生的

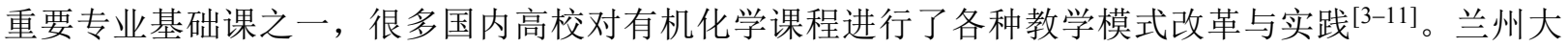
学的有机化学经过 70 多年的建设和发展, 专业优势明显, 人才培养成效显著。近年来, 我们不断进

收稿: 2020-02-12; 录用: 2020-02-20; 网络发表: 2020-03-16

“通讯作者, Email: huixp@1zu.edu.cn

基金资助: 兰州大学有机化学教学改革和课程思政示范课程项目 
行有机化学教学改革与实践, 课程教学形成了一定的特色, 本文进行了总结。

\section{2 课程目标}

有机化学课程教学秉持以学生发展为中心, 坚持创造力教育、专业与特色并举的教学理念。课 程目标包括:

(1) 知识目标: 系统掌握有机化学基础知识、基本理论和基本技能, 了解前沿新知识、新理论和 新方法。

(2) 能力目标: 具有较强实践能力、分析和解决问题的能力、创新能力和批判性思维能力, 为后 续课程和创新型化学专业人才培养奠定坚实的基础。

(3) 素质目标: 通过课程教学和素质教育结合, 充分发挥有机化学学术沉淀厚重的特点, 激发学 生的学术志趣, 培养具有高度社会责任感的化学专业人才。

\section{3 教学改革举措}

\section{1 坚持立德树人，构建了专业教育与课程思政育人有机融合的全课程育人格局}

有机化学教学坚持立德树人, 将专业教育与素质教育相结合, 充分发挥兰州大学有机化学学术 沉淀厚重的特点, 追溯黄文魁先生、朱自清先生、刘有成院士、陈耀祖院士等学术泰斗的创业情怀 和学术思想, 激发学生的学术志趣。通过 “一门八院士” 的人才培养成效, 激发和树立学生从事有 机化学科学研究的远大目标。

深入挖掘有机化学课程的思政元素和思政教育典型案例, 寓价值观引导于专业知识传授之中。 利用化学史和人物史, 尤其是有机化学家成长、追求真理的故事引导学生、教育学生; 将华人有机 化学家命名的有机化学人名反应 ${ }^{[12]}$ 融入教学中, 培养学生在科学研究中的奉献精神; 将身边的化学 知识融入思政教育, 提升学生个人素质, 增强社会责任感; 将中华民族渊源历史融入课程思政教育, 增强学生的民族自豪感和爱国意识。

\section{2 紧跟学科发展, 内容动态更新}

有机化学学科发展迅速, 科研成果日新月异。在教学中我们紧跟学科发展, 将有机化学前沿知 识不断融入教学中, 教学内容动态更新。我们在教学中增加和扩充的主要内容有: (1) 现代有机合成 新反应, 如 Suzuki 反应、Heck 反应、Negishi 反应、烯烃复分解反应、Sharpless 不对称环氧化、 Sonogashira 反应、Swern 氧化反应、Vilsmeier 反应、Kochi 反应等; (2) 强化讲授有机化学反应在合 成化学、药物化学中的重要应用; (3) 以有机合成化学为导向, 突出逆合成分析的重要性。与此同 时, 对部分教学内容进行了弱化, 主要包括: (1) 对于有机化合物的命名, 在烷烃部分全部讲清楚, 其他部分不再展开; (2) 弱化有机化合物的物理性质; (3) 在波谱解析部分, 重点讲授有机化合物的 图谱解析; (4) 对于廉价易得的有机化合物的合成和应用价值不大的有机化学反应不再讲授; (5) 基 于绿色化学发展, 删除毒性大、污染大的试剂参与的有关化学反应; (6) 通过与生物化学课程集体备 课，将氨基酸与蛋白质、核酸与核苷酸、类脂类化合物等内容安排在生物化学课程中讲授。

\section{3 改进教学方法, 提高教学质量}

有机化学课程教学坚持强化有机化学基础, 秉持突出重点、攻破难点、精益求精、深入浅出地 开展教学活动。首先, 在教学中结合课程特点, 坚持板书分析、模型教具演示等传统教学方法与 PowerPoint、Flash、ChemDraw 等软件相结合, 通过启发式教学, 设置问题情境, 启发学生思维, 充 分发挥第一课堂在教学中的重要作用。第二, 以学生为中心, 以激发学生内在学习动机为核心, 课 内、课外积极开展研讨式和学术讨论式教学 (表 1 为部分研讨课和学术讨论课主题)。结合教学内容 提出问题, 组织学生调研, 通过研讨课、学术讨论课等拓展教学内容的广度和深度。如讲授卤代烃 时, 就其在科研和生产中的应用, 组织学生进行文献调研, 开展讨论, 整理小论文。通过将教学与 科研和生产实践相结合, 有效提高了学生学习的积极性。第三, 采用案例分析法, 引导学生进行分 
析和总结。如讲授获得 2010 年诺贝尔化学奖的 Heck、Negishi 和 Suzuki 偶联反应时, 引导学生分析 反应的优点和应用范围, 提高学生分析问题和解决问题能力, 激发创新意识。又如在对映异构部分 讲授不对称合成时, 以末端炔烃对亚胺的不对称亲核加成反应合成手性炔胺为例, 通过化学文献实 例, 对底物诱导不对称合成、不对称催化 ${ }^{[13]}$ 、手性试剂 ${ }^{[14]}$ 和手性辅助不对称合成 ${ }^{[15]}$ 四种不对称合成 方法进行详细讲授, 引导学生阅读文献, 增强学生对不对称合成的认知和掌握。第四, 部分章节采 用翻转课堂。如在拔尖班教学中, 采用小班授课, 对于糖类、萜类、甾族和生物碱等章节, 学生课 前学习, 课中组织学生讲解, 教师组织讨论, 培养了学生的总结能力、PowerPoint 制作能力和语言 表达能力等。

表 1 部分研讨课和学术讨论课主题

\begin{tabular}{cl}
\hline 分组序号 & \multicolumn{1}{c}{ 研讨与讨论主题 } \\
\hline 1 & 烯烃复分解反应催化剂及其应用简介 \\
2 & 基于卤代烃的偶联反应 \\
3 & 卤代烃的应用 \\
4 & 羟基的保护和脱保护 \\
5 & 有机化学反应中的中间体 \\
6 & 氧化反应 \\
7 & 有机串联反应简介 \\
8 & Curtius 重排反应在合成化学中的应用 \\
9 & 氨基的保护和脱保护 \\
10 & 还原反应 \\
11 & 共价有机框架(COFs)材料 \\
12 & 有机光电材料 \\
13 & 萜类化合物及青蒿素的合成 \\
14 & 肽键的合成方法 \\
\hline
\end{tabular}

\section{4 立足科研优势, 科研反哺教学}

有机化学课程教学立足功能有机分子化学国家重点实验室的科研优势, 坚持将科研成果向教学 转化, 有效实现科研反哺教学。例如, 2014 年, 将团队发表在 Angew. Chem. Int.Ed.上的研究论文 ${ }^{[16]}$ 转化为有机化学实验 “2-(4-氯苯基)苯并噁唑的合成”, 向化学专业学生开放。2018 年, 将团队发表 在 Analyst 上的研究论文 ${ }^{[17]}$ 转化为综合化学实验中的化学生物学实验— “生物硫醇荧光探针: 蛋白 质中总颈基的测定和标记以及活细胞成像” , 向化学专业学生开放。2019 年进一步转化为虚拟仿真 实验教学项目, 并获批为甘肃省高等学校虚拟仿真实验教学项目。通过科研反哺教学, 提高了学生 的科研兴趣, 培养了学生的科研创新能力, 激发了学生对有机化学专业的认同感与自豪感。通过科 研成果进课堂、进教材, 形成了教学科研相互促进、相互滋养和相互支撑的良好关系, 充分发挥了 科研反哺教学在化学创新人才培养中的积极作用。

\section{5 创新人才培养模式}

在有机化学教学中, 坚持以团队教师为主体, 同时邀请国内外著名专家学者参与教学过程, 讲 授有机化学短期课程、高阶选修课程和进行专题讲座, 充分发挥学术大师的引领作用, 不断激发和 培养学生的创新意识。如芝加哥大学 Scott A. Snyder 教授连续多年讲授 “有机化学” 部分章节, 加 拿大皇家科学院院士、麦吉尔大学李朝军教授讲授 “绿色有机化学”, 北京大学裴坚教授讲授 “有 机化学中的重排反应” 专题, 复旦大学施章杰教授讲授 “现代有机合成化学” 等, 有效拓展了学生 的有机化学专业知识和学科前沿。 


\section{6 注重理论联系实际, 培养科研实践和创新能力}

课程教学注重理论联系实际, 培养学生科研实践和创新能力。如讲解核磁共振氢谱时, 带领学 生接触仪器, 解释仪器构造, 演示样品装入核磁管过程, 讲解操作步骤等, 培养学生的实践能力。 同时, 课程主讲教师承担基础化学实验和综合化学实验中的有机化学实验教学任务, 通过指导专业 实践, 强化理论联系实际, 培养学生的化学实验技能。此外, 通过本科生导师、科研导师指导学生 承担的国际级、校级大学生创新创业项目、“箬政基金” 项目、萃英创新基金项目等科研活动, 通 过科研训练提升学生的实验技能, 培养学生的科研实践和创新能力。

\section{7 坚持集体备课制度}

集体备课是提高课程授课教师素质、提高课堂教学质量的有效途径。有机化学课程教学团队主 讲教师定期进行集体备课, 组织教师集体研究课程教学大纲和教材, 分析学情、课程教学的难点和 重点, 动态更新教学内容, 完善教学计划, 反馈教学信息和教学中存在的问题, 发挥教学团队的合 作精神, 集思广益, 共同研究和探讨相应的解决方法和措施, 切实提高备课实效, 有效促进课程教 学质量不断提升。

\section{8 成绩考核}

在有机化学笔试考试中, 试题加强了有机化学反应考查(约占 36\%-40\%), 尤其注重反应的选择 性和立体化学, 适当增加了有机化学反应机理所占的比例 (20\%)。在命题中, 试题更贴近科研和生产 实践, 有机化学反应和有机合成设计重在考查具有重要应用的反应及其在合成化学中的应用。有机 化合物的结构推断试题, 全部提供化合物的实测 ${ }^{1} \mathrm{H} N M R 、 I R 、 U V$ 和 MS 图谱, 重在考查学生的图 谱解析能力。

课程成绩评价采取多元化考核方式，构建了关注学生学习过程的课程成绩评价方式。除期中考 试和期末考试外, 增加了课程单元考试。同时, 将研讨课、PowerPoint 展示、总结报告等成绩计入 课程成绩。

\section{4 创新特色}

(1) 课程教学坚持基础性与前沿性、理论性与实践性相结合的原则。

有机化学教学紧跟学科发展前沿, 教学内容动态更新, 邀请国内外专家学者讲授有机化学短期 课程、高阶选修课程和专题讲座, 发挥大师引领作用, 实现了教学内容基础性与前沿性相结合。通 过理论课教学与主讲教师指导实验课、科研训练, 实现了理论性与实践性相结合, 有效培养了学生 的实践能力和创新能力。

(2) 课程教学以学生为主体, 打造了 “两性一度” 的有机化学课程。

课程教学以学生为主体, 创新教学方法, 开设研讨课和学术讨论课, 不断拓展讲授内容的广度 与深度, 激发了学生的创新意识。坚持创造力教育, 专业与特色并举, 打造了 “两性一度” 的有机 化学课程。

(3) 实践教学平台条件先进, 有效支撑了创新型化学专业人才培养。

课程依托兰州大学功能有机分子化学国家重点实验室,学院拥有化学国家级实验教学示范中心、 国家级高等学校化学创新实验教学示范中心和国家级虚拟仿真实验教学示范中心, 良好的实践教学 平台为创新型化学专业人才培养提供了保证。

\section{5 教学效果与改革成效}

比较近三年的有机化学课程成绩, 高分成绩学生所占比例呈现逐年提高态势(图 1), 表明课程教 学设计合理、方法恰当, 评价科学, 目标达成度高。在所有学生参与的学生评教中, 有机化学教学 的评教结果连续位列学院前列, 2 位主讲教师的学生评教结果进入兰州大学前 10 名, 表明有机化学 课程教学效果满意度高。同时, 课程所有主讲教师的同行专家评教结果连续获得优秀。 

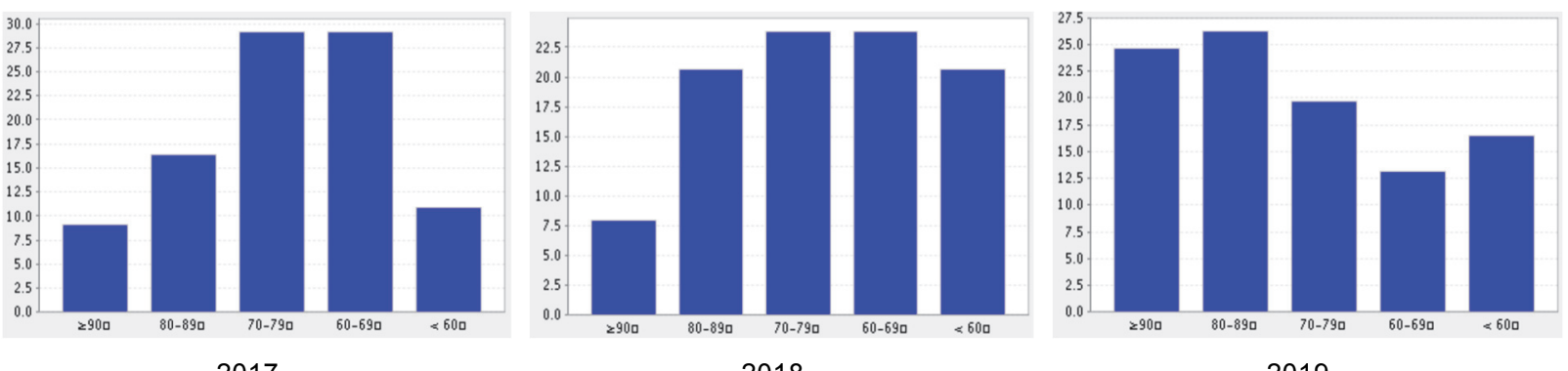

图 1 近三年有机化学期末考试成绩统计(教务管理系统截图, 依次为 2017-2019 年秋季学期)

有机化学教学研究与改革成效明显。主讲教师先后承担省部级教学研究项目 2 项, 获甘肃省教 学成果奖 2 项, 教学团队入选甘肃省教学团队。先后出版 “十一五” 国家级规划教材《有机化学》, “十二五” 规划教材《有机化学简明教程》《有机化学质疑暨考研指导》和《有机化学实验(第 4 版)》 等教材及辅导材料 4 套。

有机化学教学起到了较好的示范和辐射作用, 带动了兄弟院校的教学改革和教学水平提升, 先 后举办了 “新时期全国有机化学教学研讨班”, 承办了 “第四届全国高等学校有机化学(含实验)教学 与课程建设研讨会”, 在第二届、第五届全国高等学校有机化学教学(含实验)教学与课程建设研讨会 和第十四届全国大学化学教学研讨会上进行了大会报告。

\section{参 考 文 献}

[1] 裴坚, 朱亚先. 化学拔尖学生培养试验计划特刊, 大学化学, 2019, 34 (10), 1-150.

[2] 惠新平, 梁永民, 沈永雯. 大学化学, 2018, 33 (9), 28.

[3] 韩杰, 贺峥杰. 大学化学, 2020, 35, (7), 39.

[4] 王超, 强晓琪, 何霖俐. 教育教学论坛, 2017, No. 12, 175.

[5] 及方华, 蒋光彬. 教育教学论坛, 2019, No. 30, 103.

[6] 李银涛, 李永平, 秦志强. 化学教育 (中英文), 2017, 38 (18), 26.

[7] 郑敏燕. 大学化学, 2017, 32 (8), 20.

[8] 韩国志, 刘䜭, 关建宁. 大学化学, 2019, 34 (11), 56.

[9] 张静, 赵宇, 张大海. 化学教育, 2016, 37 (18), 24.

[10] 吕志风, 姜翠玉, 战风涛, 周玉路. 化学教育, 2016, 37 (14), 17.

[11] 江国防, 史玲, 郭灿城. 化工高等教育, 2015, No. 4, 26.

[12] 黄培强. 有机人名反应、试剂与规则. 第 2 版. 北京: 化学工业出版社, 2019.

[13] Wei, C.; Li, C.-J. J. Am. Chem. Soc. 2002, 124, 5638.

[14] Wu, T. R.; Chong, J. M. Org. Lett. 2006, 8, 15.

[15] Yin, C.; Hui, X.-P.; Xu, P.-F.; Niu, L.-F.; Chen, Y.-F.; Wang, B. Adv. Synth. Catal. 2009, 351, 357.

[16] Chen, Y.-X.; Qian, L.-F.; Zhang, W.; Han, B. Angew. Chem. Int. Ed. 2008, 47, 9330.

[17] Sun, J.; Zhang, L.; Zhang, X.; Hu, Y.; Ge, C.; Fang, J. Analyst 2016, 141, 2009. 